\title{
Effect of rubber flooring on dairy cattle stepping behavior and muscle activity
}

\author{
Eranda Rajapaksha, ${ }^{*}$ Christoph Winkler, $\dagger$ and Cassandra B. Tucker* ${ }^{* 1}$ \\ *Department of Animal Science, University of California, 1 Shields Avenue, Davis 95616 \\ †Department of Sustainable Agricultural Systems, Division of Livestock Sciences, BOKU—University of Natural Resources and Life Sciences, \\ Gregor-Mendel-Strasse 33, 1180 Vienna, Austria
}

\begin{abstract}
Use of compressible flooring, such as rubber, has increased on dairy farms. Rubber improves locomotion and is well used by cattle in preference experiments that combine walking and standing. Previous work has found that rubber is particularly beneficial for lame animals, perhaps because a softer material is particularly useful when a single hoof is compromised. The goal of this work was to evaluate the effect of flooring while standing, because cattle in freestall housing spend 40 to $50 \%$ of their time engaged in this behavior. In a $2 \times 2$ design, cows $(n=16)$ were evaluated on 4 standing surfaces that varied in terms of both floor type (concrete or rubber) and presentation [same floor under all 4 legs (all 4 legs on either concrete or rubber) or a rough surface under only one hind leg and the other 3 legs on concrete or rubber] in a crossover design. Surface electromyograms were used to evaluate muscle fatigue, total activity, and movement of muscle activity between legs during $1 \mathrm{~h}$ of standing. Muscle fatigue was evaluated in 2 contexts: (1) static contractions when cows continuously transferred weight to each hind leg, before and after $1 \mathrm{~h}$ of standing, and (2) dynamic contractions associated with steps during $1 \mathrm{~h}$ on treatment surfaces. In addition, stepping rate, time between each consecutive step, and the latency to lie down after testing were measured. No interaction between floor type and presentation was found. Presentation had a significant effect; when one hind leg was on a rough surface, cattle took 1.7 times more steps with this leg and the non-rough hind leg had 1.2 times more muscle activity, compared with when all 4 legs were on the same surface. These changes are consistent with movement away from concrete with protrusions. When standing on rubber, muscle-activity movements among legs remained stable (0.6-0.7 movements per min) over $1 \mathrm{~h}$ but increased on concrete (0.6-0.9 movements per min), indicating that, like humans, cattle may sway to counteract effects of standing. However,
\end{abstract}

Received October 2, 2014.

Accepted December 5, 2014.

${ }^{1}$ Corresponding author: cbtucker@ucdavis.edu additional work, including measurements of blood flow in the leg, is needed to fully understand the biological implications of these changes. Overall, the rubber flooring tested had little effect on standing behavior.

Key words: behavior, electromyogram, muscle activity

\section{INTRODUCTION}

Cows spend 11 to $13 \mathrm{~h} / \mathrm{d}$ standing in freestall housing systems (Ito et al., 2009). Concrete is the most common flooring material (USDA, 2009) and is a known risk factor for hoof and leg lesions (Vokey et al., 2001; Somers et al., 2003) and lameness in cattle (Cook, 2003; Vanegas et al., 2006). Use of alternatives to concrete, such as rubber, has increased during the last 2 decades (USDA, 2009) and is thought to improve cow comfort. Cows walk faster, take longer strides, and slip less (Telezhenko and Bergsten, 2005; Rushen and de Passillé, 2006) on rubber floors compared with concrete. These benefits of rubber, namely in walking speed, are more marked in lame cows compared with sound ones (Flower et al., 2007). Cows also prefer rubber over concrete when walking and standing (Telezhenko et al., 2007) and while spending time near the feed bunk (Tucker et al., 2006).

Although cattle show a clear preference for rubber, research evaluating stepping rate during forced standing on rubber (Chapinal and Tucker, 2012) or rubber surfaces that differ in compressibility (Krebs et al., 2011) has not found any differences among treatments. Other methods, such as measures of muscle function, may provide more insight into how cattle respond to standing surfaces. For example, reduced fatigue and total activity in back muscles has been used to compare compressible standing surfaces in humans (Kim et al., 1994; Madeleine et al., 1998). In addition to lacking measures of muscle function, previous comparisons of standing surfaces for cattle have involved the cows standing on all 4 legs on the same surface and used total steps taken as the dependent variable. However, stepping behavior seems to be a more promising assessment indicator in lame cows or when a disruptive surface is under a single hind leg (Neveux et al., 2006; Rushen 
et al., 2007; Rajapaksha and Tucker, 2015). Thus a protocol evaluating the effects of a rough surface under only one hind leg could provide additional insights into cattle response to standing surfaces such as rubber.

This study investigated the effect of compressibility of the standing floor on cows during $1 \mathrm{~h}$ of restricted standing, a period of time chosen because it represents the length of an average feeding bout (DeVries et al., 2003). The objective was to assess how rubber flooring affects cow stepping behavior and muscle activity when presented under all 4 legs and when a rough surface was under a single hind leg. The predictions were that cows would take fewer steps and have less muscle fatigue when standing on rubber compared with concrete, and that these benefits of rubber would be more marked when one hind leg was placed on a rough surface.

\section{MATERIALS AND METHODS}

\section{General Information}

This experiment was conducted at the University of California, Davis, dairy facility between April and May of 2012. All procedures were approved by the Institutional Animal Care and Use Committee.

\section{Animals and Housing}

A total of 16 lactating Holstein-Friesian dairy cows were tested in groups of 4 . All were clinically sound, with gait score $\leq 2$ (Flower and Weary, 2006). Cows had an average $( \pm \mathrm{SD}) \mathrm{BW}$ of $656 \pm 65 \mathrm{~kg}, \mathrm{BCS}$ of $2.8 \pm 0.2$ (Edmonson et al., 1989), DIM of $107 \pm 49$, and daily milk production of $39 \pm 1 \mathrm{~kg}$. They were in either their first $(\mathrm{n}=13)$ or second lactation $(\mathrm{n}=3)$. Cows were housed in a pen with 24 head-to-head freestalls $(1.2 \mathrm{~m}$ $\times 2.4 \mathrm{~m}$; one cow per freestall) deep bedded with sand and had a neck rail $106 \pm 2 \mathrm{~cm}$ above the stall surface. All surfaces outside the freestalls (alleyways, crossovers, walkways) were concrete. The cows were milked twice daily at 0600 and $1700 \mathrm{~h}$, had ad libitum access to water, and were fed a total mixed ration consisting of $37 \%$ alfalfa hay, $36 \%$ grain mix, $10 \%$ whole cottonseed, $12 \%$ almond hulls, $2 \%$ soybean meal, and $3 \%$ mineral mix on a DM basis. They were fed 3 times a day at 0400, 1100, and $1600 \mathrm{~h}$.

\section{Experimental Procedures}

During the experiment, animals were moved to a test area located $20 \mathrm{~m}$ away from the freestall pen. The testing area contained 4 standing stalls that were 2.4 $\mathrm{m}$ long and $1.2 \mathrm{~m}$ wide and separated by steel panels (Powder River Inc., Provo, UT; Figure 1). Each stall had 1 of 4 treatments: either concrete or rubber under all 4 legs (ALL4, either all 4 legs on concrete or all 4 legs on rubber) or these same surfaces but with one hind leg instead on a rough concrete grid (3-1ROUGH, either 3 legs on rubber and 1 on the rough surface, or 3 legs on concrete and 1 on the rough surface). The rough grid had 49 equally distributed 4 -sided trapezoidal, prism-shaped $(5.08 \times 5.08 \mathrm{~cm}$ at the base and 2 $\times 2 \mathrm{~cm}$ at the top half pyramid) protrusions from the top of each slab, created with a concrete mold. Unless specified otherwise, the concrete surfaces were poured material without any grooving and the rubber was 2 layers of revulcanized mats (38 mm thick, 4 times as compressible as concrete; Animat, Animat Inc., SaintÉlie d'Orford, Quebec, Canada). The compressibility of the rubber was tested by Anamet Inc. (Hayward, CA) using a modified ASTM D575 standard engineering technique (ASTM International, 2007), and the full results of these tests are presented by Krebs et al. (2011). All treatment surfaces were level. Location of the floors within the testing area and the disrupted area of the rough treatment were alternated and balanced among groups of 4 cows and across the experiment.

Cows were moved to treatment surfaces at approximately $0830,1000,1115$, and $1230 \mathrm{~h}$ and restrained for $1 \mathrm{~h}$ for behavior observations and surface electromyogram (SEMG) recordings. While standing in these treatment stalls, 2 horizontal metal bars kept the cow confined. They were able to move their head, look sideways, and take a few steps forward or backward, but each leg remained within its designated quadrant. Each cow was tested on a single treatment per day and had at least $22 \mathrm{~h}$ between each day of testing. The order of exposure to the 4 treatments was balanced across cows and time.

\section{Measures}

Behavioral Observations: Stepping Behavior. Five trained live observers using Etholog version 2.2 software (Ottoni, 2000) continuously recorded all steps during the 1 - $h$ tests. Observers had $r \geq 92 \%$ intra- and interobserver reliability, with the latter measured by correlation with an experienced observer (E. Rajapaksha) as a gold standard. A step was defined as lifting any part of the hoof off the ground. Steps were recorded separately for all 4 legs. Although live observation was used as the primary method to collect stepping information, for one cow on $1 \mathrm{~d}$, video recordings were used because of malfunction of the Etholog software. The video recordings were collected with 4 CVC627B color CCTV video cameras (Speco Technologies, Amityville, NY) connected to a digital video recorder with a GV1120/1240/1480 combo card (USA Vision Systems Inc., 

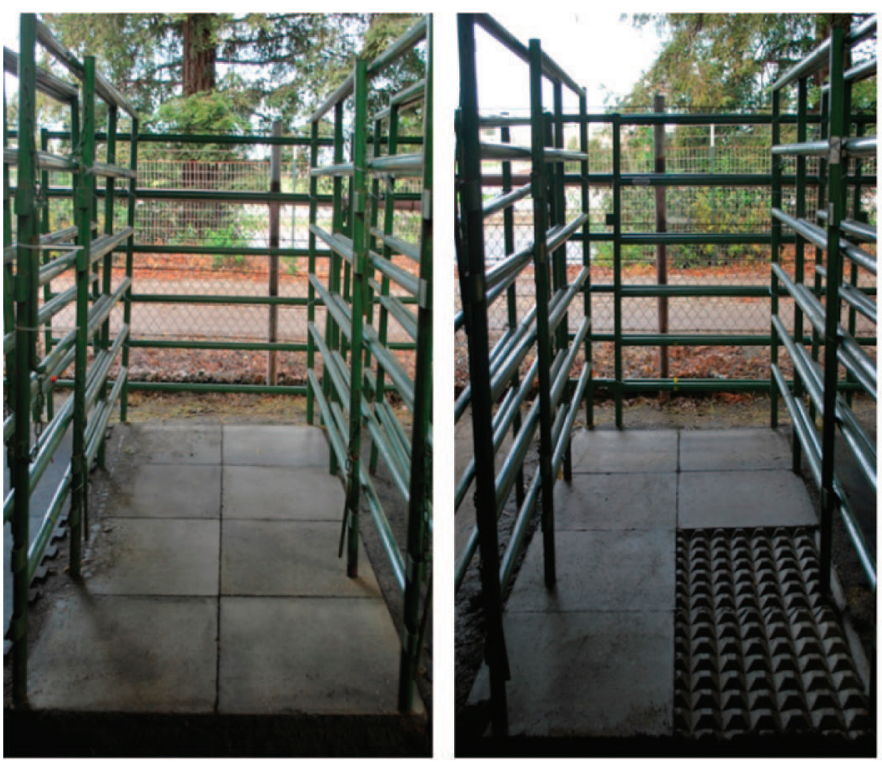

3-1ROUGH Concrete

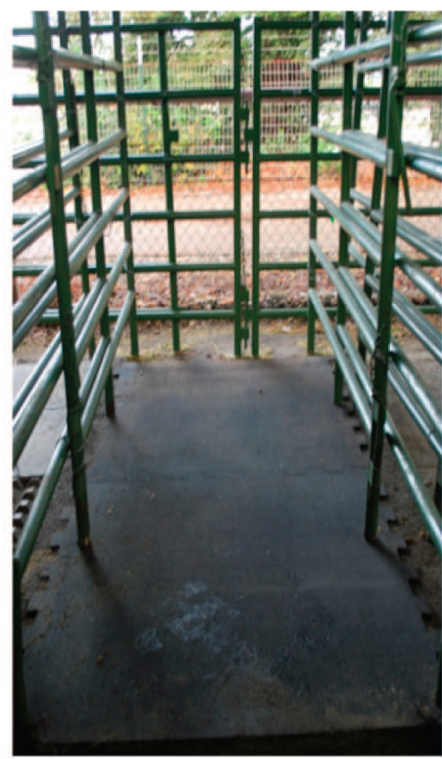

ALL4 Rubber

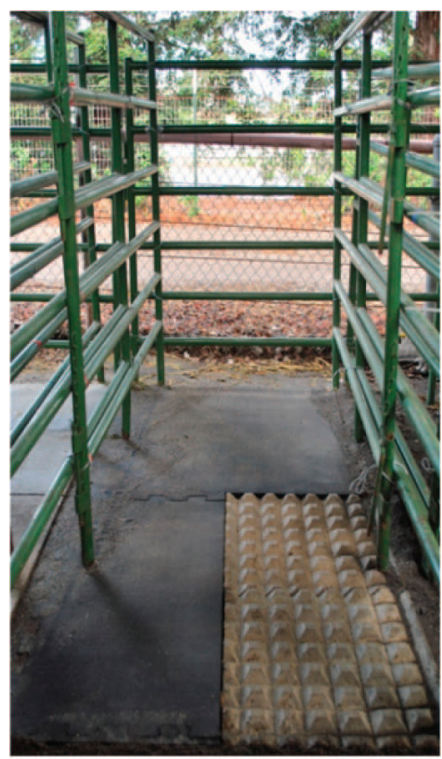

3-1ROUGH Rubber

Figure 1. Photograph illustrating the 4 treatment floors (ALL4 Concrete $=$ smooth concrete floor under all legs; $3-1 \mathrm{ROUGH}$ Concrete $=$ rough floor under one hind leg, others on concrete; ALL4 Rubber = rubber floor under all legs; 3-1ROUGH Rubber $=$ rough surface under one hind leg, others on rubber). Color version available online.

Irvine, CA) and IPD-NVR16 digital surveillance software (Clearvision Inc., Wheeling, IL). Steps were categorized in relation to the rough-treated hind leg (the leg on the rough segment of the $3-1$ ROUGH) and identified as rough-treated hind, non-rough-treated hind, contralateral front, and ipsilateral front leg. These titles were applied in all treatments to facilitate comparisons with the appropriate leg. In addition, coefficient of variation was calculated for time between steps (any leg), because we had previously found that variability is more marked with rough surfaces under all 4 legs, compared with none (Rajapaksha and Tucker, 2015).

Behavioral Observations: Lying and Standing Behavior. Lying and standing behavior were recorded with Onset Pendant G data loggers (64k, Onset Computer Corporation, Bourne, MA) for the 24 $\mathrm{h}$ before and through all $8 \mathrm{~d}$ of testing. The loggers were embedded on a silicone block, wrapped with a Vetrap cohesive bandage (3M Products, St. Paul, MN), and placed directly on the medial plane of the leg. The side of attachment (left or right) was balanced across the experiment. Loggers recorded the $\mathrm{y}$-axis at a $30-\mathrm{s}$ interval, and these data points were summarized using a special-built SAS code (UBC AWP, 2013). Isolated readings (representing both 30 and $60 \mathrm{~s}$ ) of lying and standing were deleted, following the algorithm and validation described by Ledgerwood et al. (2010). The filtered data set was used to calculate latency to lie down after testing (after end of last SEMG measure), the lengths of both the last standing and lying bouts before testing, time lying down per day, and number of lying bouts per day. These parameters were included to test whether other systematic differences (e.g., less lying before test) occurred among treatments.

SEMG Evaluations: Preparation. Before testing, cows were prepared for SEMG recordings. Eight self-adhesive bipolar surface electrodes (3M Red Dot Repositionable Electrodes, $\mathrm{Ag} / \mathrm{AgCl}$ ) were attached on the skin over the middle gluteal muscle (an extensor of the hip joint and abductor of the leg that controls hip movements) and the biceps femoris muscle (extensor of the hip and stifle and flexor of the stifle) muscle on both right and left sides of the cow. Details of skin preparation and electrode placement are explained in our previous work (Rajapaksha and Tucker, 2014). An electromyography telemetric system (Megawin Biomonitor ME 6000, Mega Electronics Ltd., Kuopio, Finland) was used to record SEMG readings during both static and dynamic muscle contractions. All SEMG signals were recorded at a sample rate of 1,000 $\mathrm{Hz}$ and were preamplified and filtered with a low-pass Butterworth filter. Common mode rejection ratio for the instrument was $110 \mathrm{~dB}$. Data recording and preparation for analysis were done with Megawin version 2.3 (Mega Electronics Ltd.). Recorded raw signals were fast Fourier transformed for frequency domain analy- 
sis, and SEMG power spectra were created and used to acquire median power frequency (MPF) values for all muscle contractions. Median amplitude (MA) and total muscle activity during the $1 \mathrm{~h}$ were calculated for statistical analysis by using the root mean square average of the raw signals.

SEMG Evaluations: Static Contractions. Static contractions were measured in the standing stalls while the cows were standing on the treatment surfaces both before and after the $1 \mathrm{~h}$ of testing. To generate static contractions, cows were forced to transfer their weight to this hind leg by placing a wooden board with fixed carriage bolts covered by a thin rubber mat (Rajapaksha and Tucker, 2014) under the other hind leg. During this process, a wooden board was placed under the other hind leg to avoid any direct effects of the treatment standing surface on the static-contraction reading (i.e., on 3-1ROUGH when one hind leg had rough surface). Readings were recorded for both muscles for $30 \mathrm{~s}$ and then repeated for the other hind leg. The order of testing (left or right first) was balanced across cows. This was done twice, once before the $1 \mathrm{~h}$ of testing and once after. Differences (after - before) of MPF and MA for values from static contractions were used to evaluate muscle fatigue (decreased MPF, increased MA, as defined by Luttman et al., 2000).

SEMG Evaluations: Continuous Recordings. Continuous SEMG recordings during standing were recorded for each 1-h test session. These recordings captured the typically low baseline muscle activity that occurred when cows were standing without lifting their legs and the increased muscle activity that occurred when they stepped. Six hind-leg steps within the first 15 min and 6 steps in the last 15 min of standing were identified. When identifying the 6 steps to analyze, the first 3 sets of right-left consecutive events (one step per leg) were chosen. The differences between the first and last $15 \mathrm{~min}$ of MPF and MA values from these steps were used to evaluate fatigue during dynamic contractions. To identify sustained muscle activity and the location of it, readings were divided into 10-s segments and categorized based on location of predominant activity (left, right, or both legs; Rajapaksha and Tucker, 2015). The number of 10 -s segments where the activity was predominantly in the right leg, left leg, or equally in both legs was counted. The activity had to be in a given location (right, left, or both) for at least $10 \mathrm{~s}$ to be included. In addition, the number of times muscle activity moved from one leg to the other or from one leg into both legs was also tabulated (muscle-activity movement). There was no minimum requirement for the amount of time associated with these movements. Two observers examined muscle-activity movements and had $r \geq 0.95$ for intra- and interobserver reliability, as measured by correlation. Total muscle activity (associated with all steps and standing activity) during the $1 \mathrm{~h}$ was calculated for each muscle type.

\section{Statistical Analysis}

All statistical analyses were performed using the cow as the experimental unit. Steps per minute for all 4 legs, each individual leg, variability in time between steps (coefficient of variation), latency to lie down, and standing and lying bouts before testing were analyzed using a general linear model (PROC GLM, SAS Institute Inc., Cary, NC). Residuals were examined to verify normality and homogeneity of variance. The model included terms for group(cow), order of exposure, floor type, presentation method, and the interaction between type and presentation. Surface electromyography values and MPF and MA values from left and right sides were averaged for each muscle for muscle-fatigue analysis during both static and dynamic contractions. Muscle fatigue (as assessed by decreased MPF, increased MA) and total combined muscle activity during $1 \mathrm{~h}$ was analyzed using the model described above.

To examine the effect of time within the 1-h test, steps per minute, total combined muscle activity, and muscle-activity shifts were calculated for four 15-min intervals. These values were then tested using a model that included terms for group(cow); order of exposure; time; floor type; floor presentation method; and 3-way interactions between time, floor type, and presentation method. This model incorporated a Greenhouse-Geisser correction.

\section{RESULTS}

Floor type and presentation method did not significantly interact for any of the parameters $(P \geq 0.124)$. Thus, all results are presented relative to the main effects (floor type or presentation method) and interactions with time.

\section{Behavioral Observations: Stepping Behavior}

Steps per minute did not change in response to floor type $\left(F_{1,42} \leq 1.9, P \geq 0.170\right)$. Compared with ALL4 floors, cows on $3-1$ ROUGH took more steps per minute with the rough-treated leg and fewer with the 3 legs on flat surfaces (Table 1). Cows tended to have a higher coefficient of variation in time between steps on 3-1ROUGH treatments compared with ALL4 $\left(F_{1,42}=\right.$ $3.1, P=0.082$; Table 1$)$. Changes in steps per minute from all 4 legs over time were more marked in ALL4, 
Table 1. Mean steps per minute (LSM, SE) during $1 \mathrm{~h}$ of standing on flooring presented in 2 ways

\begin{tabular}{|c|c|c|c|c|}
\hline \multirow[b]{2}{*}{ Item } & \multicolumn{2}{|c|}{ Presentation of floor ${ }^{1}$} & \multirow[b]{2}{*}{$\mathrm{SE}$} & \multirow[b]{2}{*}{$P$-value } \\
\hline & ALL4 & 3-1ROUGH & & \\
\hline \multicolumn{5}{|l|}{ Steps per minute } \\
\hline Rough-treated hind leg $^{2}$ & 1.7 & 2.9 & 0.10 & $<0.001$ \\
\hline Non-rough-treated hind leg & 1.8 & 0.9 & 0.07 & $<0.001$ \\
\hline Both hind legs combined & 3.6 & 3.9 & 0.14 & 0.098 \\
\hline Contralateral front leg & 0.8 & 1.2 & 0.07 & 0.001 \\
\hline Ipsilateral front leg & 0.9 & 0.7 & 0.05 & 0.007 \\
\hline Both front legs & 1.7 & 1.8 & 0.05 & 0.286 \\
\hline All 4 legs & 5.3 & 5.8 & 0.21 & 0.103 \\
\hline \multicolumn{5}{|l|}{ Time between steps } \\
\hline CV $(\%)$ & 192 & 202 & 3.9 & 0.083 \\
\hline
\end{tabular}

${ }^{1} 3-1$ ROUGH $=$ rough concrete surface under 1 hind leg, concrete or rubber under other 3 legs; ALL4 = concrete or rubber surfaces under all legs.

${ }^{2}$ Hind leg placed on rough-portion floor on 3-1ROUGH treatment.

compared with $3-1$ ROUGH (time $\times$ presentation; $F_{3,126}$ $=4.9, P=0.006 ;$ Figure 2). Floor type also tended to influence changes in steps per minute over time (time $\times$ floor type; $F_{3,126}=2.5, P=0.071$; Figure 2$)$, with stepping rate increasing more rapidly on rubber than on concrete.

On average, cows spent $11 \pm 2.3 \mathrm{~h} / \mathrm{d}$ lying down and had $10 \pm 4$ lying bouts per day (mean \pm SD). Treatments did not differ in the latency to lie down after testing $\left(61 \pm 46.7\right.$ min; mean $\pm \mathrm{SD} ; F_{1,42}=0.3, P \geq$ $0.569)$. Similarly, there were no differences $\left(F_{1,42} \leq 0.2\right.$, $P \geq 0.335)$ in either standing $(52 \pm 25 \mathrm{~min})$ or lying time $(64 \pm 49 \mathrm{~min})$ immediately before the cows were tested on the treatments.

\section{SEMG Evaluations}

Muscle-Activity Location and Movement. In the 3-1ROUGH treatments, muscle activity was located in the non-rough-treated leg more often than ALL4 $\left(F_{1,42}\right.$ $=265, P<0.001$, Table 2$)$. Muscle-activity movements between hind legs did not differ for any of the floor type or presentation combinations $\left(F_{1,42} \leq 1.2, P \geq 0.287\right.$; Table 2). However, muscle-activity movements between legs increased over time on concrete but remained relatively stable on rubber (time $\times$ floor type, $F_{3,126}=3.5$, $P=0.018$; Figure 3 ).

Total Muscle Activity and Muscle Fatigue. Total muscle activity produced by both hind legs combined was higher on 3-1ROUGH floors compared with ALL4 $\left(F_{1,42}=5.8, P=0.019\right.$; Table 3$)$. Muscle activity in the non-rough-treated hind leg was significantly higher $\left(F_{1,42}=20.4, P<0.001\right.$; Table 3$)$. Muscle activity of the middle gluteal muscle was significantly higher $\left(F_{1,42}=6.4, P=0.015\right.$; Table 3$)$ on 3-1ROUGH floors, but this pattern was not seen in the biceps femoris.
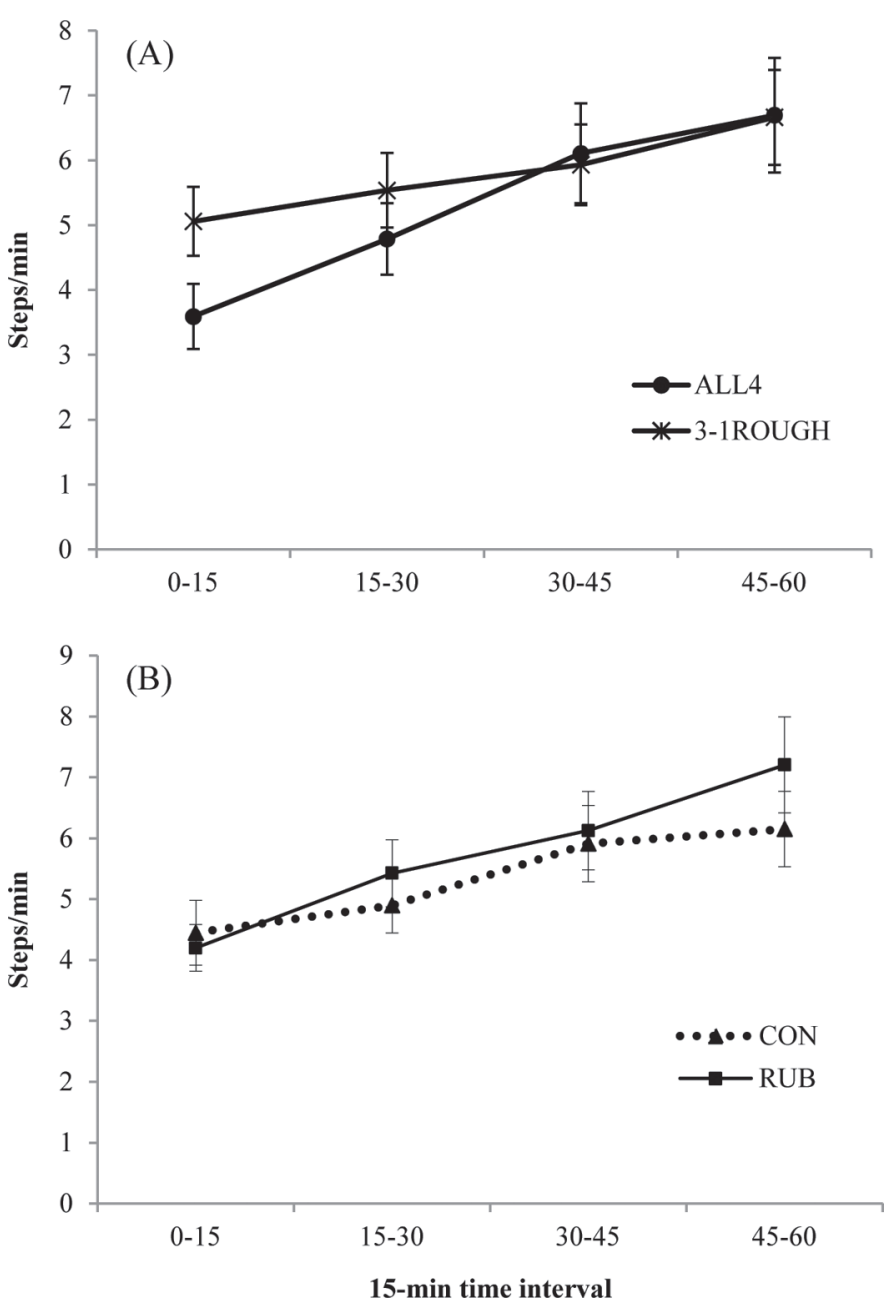

Figure 2. Steps per minute in 15-min time intervals (LSM, SE) on both hind legs combined for each presentation method (ALL4 $=$ all 4 legs on the same surface; $3-1$ ROUGH $=1$ hind leg on a rough surface, 3 legs on the same surface; panel A) and 2 floor types (CON vs. RUB panel $\mathrm{B}$ ) over $1 \mathrm{~h}$ of standing. $\mathrm{CON}=$ concrete; $\mathrm{RUB}=$ rubber. 
Table 2. Number of 10-s segments categorized based on location of predominant activity in the rough-treated hind leg, the non-rough-treated hind leg, and both hind legs combined (LSM, SE), and total number of muscleactivity movements between legs during $1 \mathrm{~h}$ of standing on floors presented in 2 ways

\begin{tabular}{|c|c|c|c|c|}
\hline \multirow[b]{2}{*}{ Item } & \multicolumn{2}{|c|}{ Presentation of floor ${ }^{1}$} & \multirow[b]{2}{*}{$\mathrm{SE}$} & \multirow[b]{2}{*}{$P$-value } \\
\hline & ALL 4 & 3-1 ROUGH & & \\
\hline \multicolumn{5}{|l|}{ Muscle-activity location/min } \\
\hline Rough-treated hind leg ${ }^{2}$ & 0.4 & 0.3 & 0.02 & $<0.001$ \\
\hline Non-rough-treated hind leg & 0.4 & 1.4 & 0.04 & $<0.001$ \\
\hline Both hind legs & 1.3 & 0.6 & 0.05 & $<0.001$ \\
\hline \multicolumn{5}{|l|}{ Muscle-activity movements/min } \\
\hline Movements between hind legs & 0.7 & 0.6 & 0.03 & 0.377 \\
\hline
\end{tabular}

Total combined muscle activity did not differ between concrete and rubber surfaces $\left(F_{1.42} \leq 2.7, P \geq 0.102\right.$; Table 3).

Both presentation and floor type affected how total combined muscle activity changed with time. It was higher on 3-1ROUGH compared with ALL4 in the first half hour and then became very similar (time $\times$ presentation, $F_{3,126}=5.2, P=0.006$; Figure 4). Muscle activity fluctuated on concrete floors but appeared to increase steadily on rubber (time $\times$ floor type, $F_{3,126}$ $=2.6, P=0.069$; Figure 4). There were no differences in MPF and MA indicative of fatigue for either static (Table 4) or dynamic (Table 5) contractions between the start and end of the $1 \mathrm{~h}$. The MPF in the biceps femoris muscle of the rough-treated leg $\left(F_{1,42}=5.6, P\right.$ $=0.022$; Table 4 ) was reduced, but it was not accompanied by a significant MA increase, as required for the definition of fatigue used.

\section{DISCUSSION}

The current study compared the effects of both floor type and presentation method on dairy cow behavior and muscle activity. When cows stood with one hind leg on rough concrete, they moved away from this stimulus; that is, they took more steps with the rough-treated leg and the non-rough-treated leg had more muscle activity. The flooring under the other 3 legs did not affect this response. Although muscle fatigue was not seen in any of the treatments, rubber flooring resulted in timedependent changes in muscle activity, indicating cows move muscle activity between legs more the longer they stand on concrete, compared with rubber.

When cows stood with one hind leg on rough concrete they took more steps, indicating that they tried to move away from these protrusions. This finding is similar to that of other work with the same $3-1$ ROUGH

Table 3. Total muscle activity ( $\mu \mathrm{Vs}$, least-squared means, SE) during $1 \mathrm{~h}$ of standing on floors that varied in both type and presentation

\begin{tabular}{|c|c|c|c|c|c|c|c|}
\hline \multirow[b]{2}{*}{ Item } & \multicolumn{2}{|c|}{ Floor type $^{1}$} & \multirow[b]{2}{*}{$P$-value } & \multicolumn{2}{|c|}{ Presentation of floor ${ }^{2}$} & \multirow[b]{2}{*}{$P$-value } & \multirow[b]{2}{*}{$\mathrm{SE}$} \\
\hline & $\mathrm{CON}$ & RUB & & ALL4 & 3-1ROUGH & & \\
\hline Both hind legs averaged & 435 & 437 & 0.929 & 421 & 451 & 0.019 & 8.7 \\
\hline Rough-treated hind leg ${ }^{3}$ & 412 & 430 & 0.539 & 446 & 397 & 0.097 & 20.4 \\
\hline Non-rough-treated hind leg & 459 & 443 & 0.519 & 396 & 505 & $<0.001$ & 17.1 \\
\hline \multicolumn{8}{|l|}{ Rough-treated hind leg } \\
\hline Biceps femoris & 231 & 229 & 0.821 & 230 & 231 & 0.900 & 6.8 \\
\hline Middle gluteal & 593 & 631 & 0.480 & 662 & 563 & 0.070 & 37.6 \\
\hline \multicolumn{8}{|l|}{ Non-rough-treated hind leg } \\
\hline Biceps femoris & 210 & 193 & 0.102 & 192 & 211 & 0.065 & 7.4 \\
\hline Middle gluteal & 707 & 693 & 0.745 & 601 & 799 & $<0.001$ & 30.0 \\
\hline \multicolumn{8}{|l|}{ Both hind legs averaged } \\
\hline Biceps femoris & 221 & 211 & 0.252 & 211 & 221 & 0.221 & 6.0 \\
\hline Middle gluteal & 650 & 662 & 0.540 & 631 & 681 & 0.015 & 13.8 \\
\hline
\end{tabular}

${ }^{1} \mathrm{CON}=$ concrete; $\mathrm{RUB}=$ rubber.

${ }^{2} 3-1$ ROUGH $=$ rough concrete surface under 1 hind leg, concrete or rubber under other 3 legs; ALL4 = concrete or rubber surfaces under all legs.

${ }^{3}$ Hind leg placed on rough-portion floor on 3-1ROUGH. 


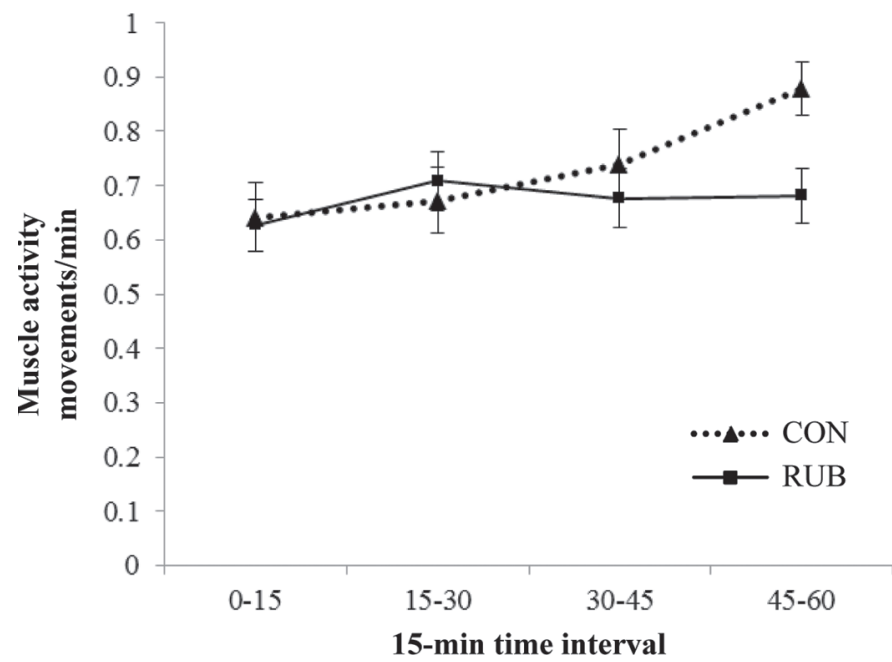

Figure 3. Number of muscle-activity movements between hind legs per minute (LSM, SE) over $1 \mathrm{~h}$ of standing on 2 floor types (CON or RUB). $\mathrm{CON}=$ concrete; $\mathrm{RUB}=$ rubber

protocol (Rajapaksha and Tucker, 2015) and where rocks or screws were under a single hind leg (Neveux et al., 2006; Rushen et al., 2007): cows took more steps with the rough-treated hind leg and fewer steps on the non-rough-treated hind leg and the ipsilateral front leg, compared with when all legs were on the same surface. Muscle activity was lower in the rough-treated hind leg but significantly higher in the corresponding nonrough-treated hind leg.

We predicted that rubber flooring would alleviate some of the effects of a rough surface under a single hind leg. Previous work has found that rubber surfaces that were 7 to 12 times more compressible than concrete (Rushen and de Passillé, 2006) resulted in a more marked improvement in gait measurements for lame cows than for sound ones (Flower et al., 2007), indicating that rubber is more comfortable for compromised animals. Although cows tried to move away from the rough surface under one hind leg in the current work, rubber flooring did not change their response to this stimulus. Perhaps the surface tested here (4 times more compressible than concrete, Krebs et al., 2011) did not provide enough cushion to see a benefit. In addition, rubber differs from concrete in other ways besides compressibility, so the advantages in terms of cow choice and for lame cows may be because of benefits associated with walking, rather than when standing in one location.

Measuring responses to flooring under all 4 legs while standing in one location remains a challenge. Both the current and previous work have been unable to differentiate rubber and concrete using stepping rate while standing as an indicator (Krebs et al., 2011; Chapinal
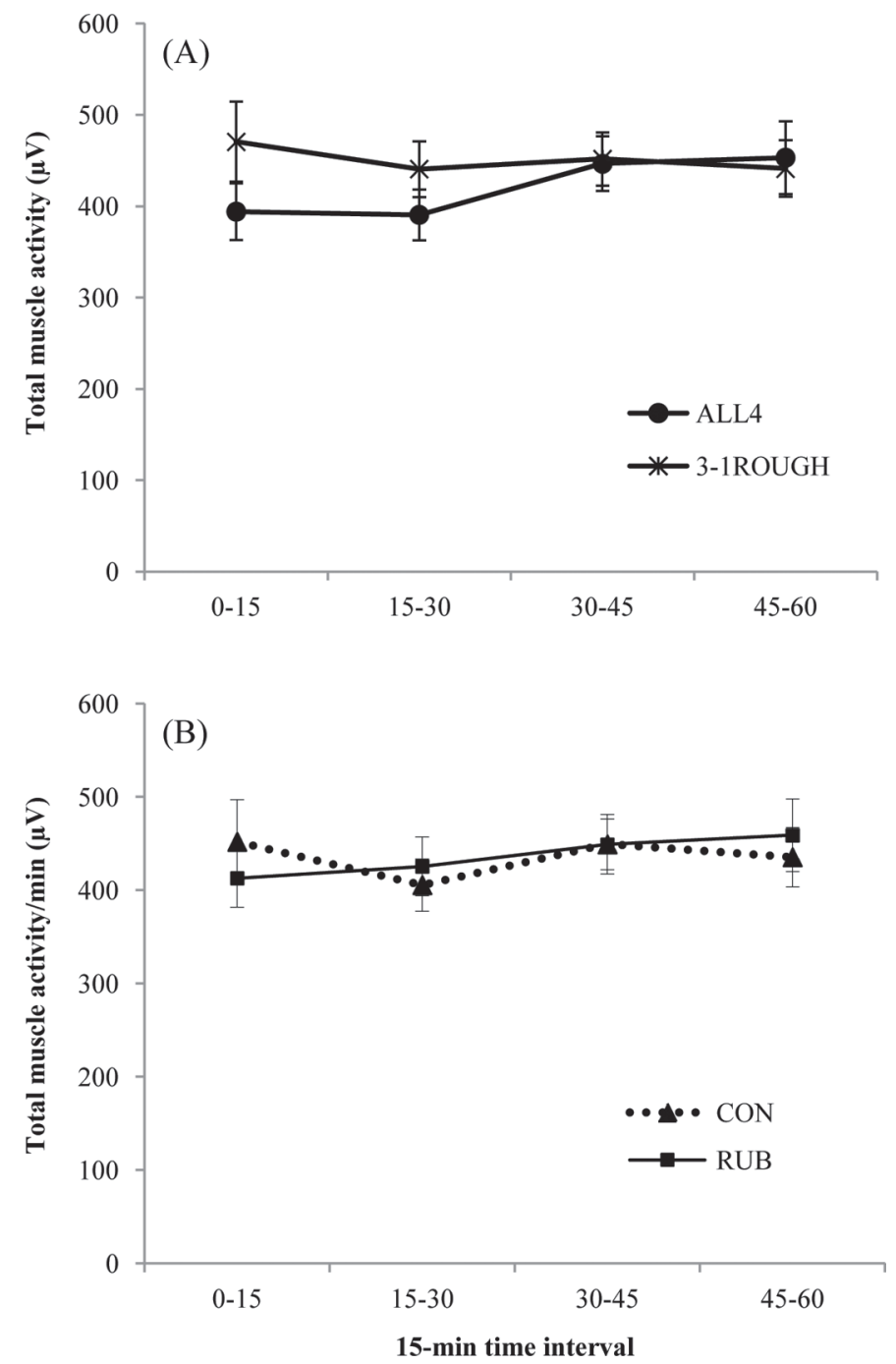

Figure 4. Total muscle-activity change ( $\mu \mathrm{V}$ for both middle gluteal and biceps femoris muscles; LSM, SE) for both hind legs combined for each presentation method (ALL4 = all 4 legs on the same surface; $3-1$ ROUGH $=1$ hind leg on a rough surface, 3 legs on the same surface; panel A) and 2 floor types (CON vs. RUB; panel B) over $1 \mathrm{~h}$ of standing. $\mathrm{CON}=$ concrete; $\mathrm{RUB}=$ rubber.

and Tucker, 2012). We have previously found that time taken between steps is more variable when a rough surface is under all 4 legs, compared with when cows stand on smooth concrete, but having a rough surface under a single leg had no effect on this parameter (Rajapaksha and Tucker, 2015). In contrast, in the current study, the time between steps tended to be more variable on 3-1ROUGH compared with ALL4. The discrepancy of the findings between these 2 studies makes it difficult to explain the biological significance of this response and raises further questions about if and how cattle respond to restraint on a specific surface as during routine health checks and while waiting for milking. 
Table 4. Median power frequency (MPF; Hz) and median amplitude (MA; $\mu$ V) value differences (LSM, SE) between start and end of $1 \mathrm{~h}$ measured for biceps femoris and middle gluteal muscles measured for all floor types and presentation of the surface from static contractions measured by forcing cows to transfer weight to one hind leg

\begin{tabular}{|c|c|c|c|c|c|c|c|}
\hline \multirow[b]{2}{*}{ Item } & \multicolumn{2}{|c|}{ Floor type $^{1}$} & \multirow[b]{2}{*}{$P$-value } & \multicolumn{2}{|c|}{ Presentation of the floor ${ }^{2}$} & \multirow[b]{2}{*}{$P$-value } & \multirow[b]{2}{*}{$\mathrm{SE}$} \\
\hline & CON & RUB & & ALL4 & 3-1ROUGH & & \\
\hline \multicolumn{8}{|c|}{ Rough-treated hind leg $^{3}$} \\
\hline \multicolumn{8}{|c|}{ Biceps femoris } \\
\hline MA & 0.36 & -1.55 & 0.324 & 0.64 & -1.82 & 0.203 & 1.34 \\
\hline MPF & -7.43 & 0.31 & 0.022 & -4.69 & -2.44 & 0.487 & 2.27 \\
\hline \multicolumn{8}{|c|}{ Middle gluteal } \\
\hline MA & 6.32 & 5.88 & 0.944 & 7.33 & 4.87 & 0.675 & 4.40 \\
\hline MPF & 1.00 & 5.73 & 0.109 & 3.25 & 3.48 & 0.936 & 2.02 \\
\hline \multicolumn{8}{|c|}{ Non-rough-treated hind leg } \\
\hline \multicolumn{8}{|c|}{ Biceps femoris } \\
\hline MA & -0.29 & -1.17 & 0.637 & 0.57 & -2.03 & 0.167 & 1.31 \\
\hline MPF & 1.51 & 2.15 & 0.835 & -0.73 & 4.38 & 0.104 & 2.18 \\
\hline \multicolumn{8}{|c|}{ Middle gluteal } \\
\hline MA & -3.19 & 0.39 & 0.504 & -4.31 & 1.50 & 0.281 & 3.76 \\
\hline MPF & 1.97 & 3.91 & 0.437 & 1.30 & 4.58 & 0.197 & 1.75 \\
\hline
\end{tabular}

${ }^{1} \mathrm{CON}=$ concrete; $\mathrm{RUB}=$ rubber.

${ }^{2} 3-1$ ROUGH $=$ rough concrete surface under 1 hind leg, concrete or rubber under other 3 legs; ALL4= concrete or rubber surfaces under all legs.

${ }^{3}$ Hind leg placed on rough-portion floor on 3-1ROUGH.

Although there were no treatment differences detected by steps per minute, rubber floors had time-dependent effects on muscle-activity movements, compared with concrete. Over the $1 \mathrm{~h}$ of standing, muscle-activity movements between hind legs increased on the concrete floor but remained relatively stable on rubber. In humans, postural sway is a similar behavior that involves shifting muscle activity and weight between legs to re- duce discomfort during standing (Landry et al., 2010). Thus, the increase in muscle-activity movements may act as a mechanism, other than stepping, to counteract effects of standing. However, more research is needed to evaluate this idea because only time-dependent changes were seen in the current study and this result has not been replicated in previous work; muscle-activity movements did not differ when cows stood entirely on rough

Table 5. Mean median power frequency (MPF; Hz) and median amplitude (MA; $\mu$ V) differences (LSM, SE) associated with dynamic contractions at the start and end of $1 \mathrm{~h}$ of standing ${ }^{1}$

\begin{tabular}{|c|c|c|c|c|c|c|c|}
\hline \multirow[b]{2}{*}{ Item } & \multicolumn{2}{|c|}{ Floor type ${ }^{2}$} & \multirow[b]{2}{*}{$P$-value } & \multicolumn{2}{|c|}{ Presentation of the floor ${ }^{3}$} & \multirow[b]{2}{*}{$P$-value } & \multirow[b]{2}{*}{$\mathrm{SE}$} \\
\hline & $\mathrm{CON}$ & RUB & & ALL4 & 3-1ROUGH & & \\
\hline \multicolumn{8}{|c|}{ Rough-treated leg ${ }^{4}$} \\
\hline \multicolumn{8}{|c|}{ Biceps femoris } \\
\hline MA & -2.23 & -0.23 & 0.171 & -0.16 & -2.29 & 0.339 & 1.46 \\
\hline MPF & 2.80 & -4.08 & 0.091 & -1.24 & -0.04 & 0.765 & 2.83 \\
\hline \multicolumn{8}{|c|}{ Middle gluteal } \\
\hline MA & -1.70 & -0.14 & 0.092 & -1.25 & -0.59 & 0.644 & 1.13 \\
\hline MPF & 1.35 & -1.06 & 0.357 & -1.61 & 1.90 & 0.182 & 1.83 \\
\hline \multicolumn{8}{|c|}{ Non-rough-treated hind leg ${ }^{4}$} \\
\hline \multicolumn{8}{|c|}{ Biceps femoris } \\
\hline MA & -1.70 & -0.14 & 0.333 & -1.25 & -0.59 & 0.677 & 1.13 \\
\hline $\mathrm{MPF}$ & 1.36 & -0.92 & 0.426 & 1.09 & -0.65 & 0.523 & 2.00 \\
\hline \multicolumn{8}{|c|}{ Middle gluteal } \\
\hline MA & -2.59 & 8.13 & 0.046 & 2.17 & 3.37 & 0.819 & 3.69 \\
\hline MPF & 2.66 & -0.48 & 0.179 & 1.17 & 1.00 & 0.941 & 1.62 \\
\hline
\end{tabular}

${ }^{1}$ These values were measured in biceps femoris and middle gluteal muscles while cattle stood for $1 \mathrm{~h}$ on 2 types of floors, presented in 2 ways.

${ }^{2} \mathrm{CON}=$ concrete $\mathrm{RUB}=$ rubber.

${ }^{3} 3-1$ ROUGH $=$ rough concrete surface under 1 hind leg, concrete or rubber under other 3 legs; ALL4 = concrete or rubber surfaces under all legs.

${ }^{4}$ Hind leg placed on rough-portion floor on 3-1ROUGH. 
floors compared with smooth concrete (Rajapaksha and Tucker, 2015). In addition, other biological consequences of the parameters reported here, both stepping and movement of muscle activity, could provide insight into why cattle engage in both of these responses. In humans, both fidgeting and postural swaying reduce discomfort and fatigue by increased blood circulation to muscle and reduced venous pooling (Freitas et al., 2005). It would be worthwhile to examine the relationships among shifts in muscle activity, stepping, and venous pooling during standing in cattle to understand the biological function of the behavioral and physiological changes observed.

Regardless of floor type or presentation method, cattle did not experience fatigue (as measured by changes in MPF and MA) over the $1 \mathrm{~h}$ of standing. Similarly, when SEMG were used on cows to evaluate muscle fatigue, there was no indication of fatigue when comparing MPF and MA values at the start and end of 90 min standing (Rajapaksha and Tucker, 2014) and $1 \mathrm{~h}$ of standing (Rajapaksha and Tucker, 2015). In the current study, significant MPF reduction was observed on the concrete surfaces without corresponding MA increase; thus, this change did not meet the definition of fatigue used by Luttman et al. (2000). It seems likely that cattle are able to stand for at least $2 \mathrm{~h}$ /bout without experiencing fatigue (e.g., in the current work 1 $\mathrm{h}$ of testing and almost $1 \mathrm{~h}$ of standing, on average, beforehand) and that consideration of longer periods of time, such as those associated with wait times for milking and health-check-related restraint, may yield different results.

\section{CONCLUSIONS}

When rough flooring was under a single leg, cattle increased stepping rate and muscle activity, consistent with moving this leg away from the protrusions. These patterns were present irrespective of floor type. Cattle showed more muscle-activity movements between hind legs when they had stood on concrete for $1 \mathrm{~h}$, compared with rubber, but the biological implications of this change are unclear. Overall, rubber flooring had little effect on standing behavior.

\section{ACKNOWLEDGMENTS}

This research was supported by the W. K. Kellogg Endowment, Lyons fellowship (funding for Eranda Rajapaksha), and USDA National Institute of Food and Agriculture Multistate Research Project NC1029. We gratefully acknowledge the infrastructure support of the Department of Animal Science, College of Agricultural and Environmental Sciences, and the California
Agricultural Experiment Station of the University of California-Davis (UC Davis). We also thank UC Davis dairy farm manager Doug Gisi, Joseph Banuelos (UC Davis), and the UC Davis undergraduate interns for their help throughout the experiments. We are also grateful to the UC Davis Veterinary orthopedic laboratory for sharing their equipment and software.

\section{REFERENCES}

ASTM International. 2007. ASTM D575-91. Standard test methods for rubber properties in compression. ASTM International, West Conshohocken, PA.

Chapinal, N., and C. B. Tucker. 2012. Validation of an automated method to count steps while cows stand on a weighing platform and its application as a measure to detect lameness. J. Dairy Sci. 95:6523-6528.

Cook, N. B. 2003. Prevalence of lameness among dairy cattle in Wisconsin as a function of housing type and stall surface. J. Am. Vet. Med. Assoc. 223:1324-1328.

DeVries, T. J., M. A. G. von Keyserlingk, D. M. Weary, and K. A. Beauchemin. 2003. Measuring the feeding behavior of lactating dairy cows in early to peak lactation. J. Dairy Sci. 86:3354-3361.

Edmonson, A. J., I. J. Lean, L. D. Weaver, T. Farve, and G. Webster. 1989. A body condition scoring chart for Holstein dairy cows. J. Dairy Sci. 72:68-78.

Flower, F. C., A. M. de Passillé, D. M. Weary, D. J. Sanderson, and J. Rushen. 2007. Softer, higher-friction flooring improves gait of cows with and without sole ulcers. J. Dairy Sci. 90:1235-1242.

Flower, F. C., and D. M. Weary. 2006. Effect of hoof pathologies on subjective assessments of dairy cow gait. J. Dairy Sci. 89:139-146.

Freitas, S. M. S. F., S. A. Wieczorek, P. H. Marchetti, and M. Duarte. 2005. Age-related changes in human postural control of prolonged standing. Gait Posture 22:322-330.

Ito, K., D. M. Weary, and M. A. G. von Keyserlingk. 2009. Lying behavior: Assessing within and between herd variation in freestall housed dairy cows. J. Dairy Sci. 92:4412-4420.

Kim, J. Y., C. Stuart-Buttle, and W. S. Marras. 1994. The effects of mats on back and leg fatigue. Appl. Ergon. 25:29-34.

Krebs, N., S. L. Berry, and C. B. Tucker. 2011. Restless behavior increases over time, but not with compressibility of the flooring surface, during forced standing at the feed bunk. J. Dairy Sci. 94:97-105.

Landry, S. C., B. M. Nigg, and K. E. Tecante. 2010. Standing in an unstable shoe increases postural sway and muscle activity of selected smaller extrinsic foot muscles. Gait Posture 32:215-219.

Ledgerwood, D. N., C. Winckler, and C. B. Tucker. 2010. Evaluation of data loggers, sampling intervals, and editing techniques for measuring lying behavior of dairy cattle. J. Dairy Sci. 93:5129-5139.

Luttman, L., J. Mattias, and L. Wolfgang. 2000. Electromyographical indication of muscular fatigue in occupational field studies. Int. J. Ind. Ergon. 25:645-660.

Madeleine, P., M. Voigt, and L. Arendt-Nielsen. 1998. Subjective, physiological and biomechanical responses to prolonged manual work performed standing on hard and soft surfaces. Eur. J. Appl. Physiol. Occup. Physiol. 77:1-9.

Neveux, S., D. M. Weary, J. Rushen, M. A. G. von Keyserlingk, and A. M. de Passillé. 2006. Hoof discomfort changes how dairy cattle distribute their body weight. J. Dairy Sci. 89:2503-2509.

Ottoni, E. B. 2000. EthoLog 2.2-A tool for the transcription and timing of behavior observation sessions. Behav. Res. Methods Instrum. Comput. 32:446-449.

Rajapaksha, E., and C. B. Tucker. 2014. How do cattle respond to sloped floors? An investigation using behavior and electromyograms. J. Dairy Sci. 97:2808-2815.

Rajapaksha, E., and C. B. Tucker. 2015. Stepping behavior and muscle activity of dairy cows on uncomfortable standing surfaces presented under 1 or 4 legs. J. Dairy Sci. 98:295-304. 
Rushen, J., and A. M. de Passillé. 2006. Effects of roughness and compressibility of flooring on cow locomotion. J. Dairy Sci. 89:29652972.

Rushen, J., E. Pombourcq, and A. M. de Passillé. 2007. Validation of two measures of lameness in dairy cows. Appl. Anim. Behav. Sci. 106:173-177.

Somers, J. G. C. J., K. Frankena, E. N. Noordhuizen-Stassen, and J. H. M. Metz. 2003. Prevalence of claw disorders in Dutch dairy cows exposed to several floor systems. J. Dairy Sci. 86:2082-2093.

Telezhenko, E., and C. Bergsten. 2005. Influence of floor type on the locomotion of dairy cows. Appl. Anim. Behav. Sci. 93:183-197.

Telezhenko, E., L. Lidfors, and C. Bergsten. 2007. Dairy cow preferences for soft or hard flooring when standing or walking. J. Dairy Sci. 90:3716-3724.

Tucker, C. B., D. M. Weary, A. M. de Passillé, B. Campbell, and J. Rushen. 2006. Flooring in front of the feed bunk affects feed- ing behavior and use of freestalls by dairy cows. J. Dairy Sci. 89:2065-2071.

UBC AWP (University of British Columbia Animal Welfare Program). 2013. UBC Animal Welfare Program: SOP HOBO Data Loggers. University of British Columbia, Vancouver, Canada.

USDA. 2009. Dairy 2007, Part V: Changes in Dairy Cattle Health and Management Practices in the United States 1996-2007. \#519.0709. USDA:Animal and Plant Health Inspection Service:Veterinary Services, Center for Epidemiology and Animal Health, Fort Collins, CO.

Vanegas, J., M. Overton, S. L. Berry, and W. M. Sischo. 2006. Effect of rubber flooring on claw health in lactating dairy cows housed in free-stall barns. J. Dairy Sci. 89:4251-4258.

Vokey, F. J., C. L. Guard, H. N. Erb, and D. M. Galton. 2001. Effects of alley and stall surfaces on indices of claw and leg health in dairy cattle housed in a free-stall barn. J. Dairy Sci. 84:2686-2699. 